\title{
Game technologies as a tool of motivation and improvement the quality of university students' training
}

\author{
E.F. Mazanyuk $^{1 *}$, A.L. Tretyakov ${ }^{2}$, and L.R. Amichba ${ }^{3}$ \\ ${ }^{1}$ V.I. Vernadsky Crimean Federal University, Simferopol, Russia \\ ${ }^{2}$ Moscow Region State University, Mytishchi, Russia \\ ${ }^{3}$ Federal State Budgetary Educational Institution of Higher Education "Russian Academy of National \\ Economy and Public Administration under the President of the Russian Federation", Kirov branch, \\ Kirov, Russia
}

\begin{abstract}
The article discusses and describes in detail the specifics of equipping the system of higher professional education with tools of modern pedagogical technologies - game technologies that have a significant impact on the quality of professional training of future specialists and their motivation to obtain general and special competencies. The most relevant game technologies are considered separately. and their effectiveness (or inefficiency) is confirmed by means of a survey of leading teachers of the Crimea who actively use game technologies in their teaching practice. In addition. a significant segment of the study is devoted to reviewing and comparing the experience of predecessors in this matter. The role of various pedagogical approaches in the system of higher professional education is identified and updated. and their separate elements. especially significant for research. are highlighted. The author compares the opinions of various scientists (both practitioners and theoretical researchers) who address the study of the system of modern pedagogical technologies in general and game technologies in particular. on the basis of which a comprehensive conclusion is made. which is reflected in the final part of the article. A special place in the structure of the study is occupied by the selected key method - a questionnaire based on data provided by more than 100 teachers of higher and secondary professional education. This method is one of the most effective and promising methods of scientific-analytical and reflexive research. which is especially important in the framework of pedagogical science.
\end{abstract}

\section{A problem statement}

The system of higher professional education is mostly experience a certain range of changes nowadays. according to which the range of problems and crisis aspects related to both organizational and managerial and educational activities is clearly outlined in the conditions of modern pedagogical knowledge. Today. there is an abundance of tools. means

*Corresponding author: ipcs-profped@yandex.ru 
and mechanisms of external and internal influence on the process of optimizing and modernizing the system of professional training of higher school students $[13 ; 14 ; 18 ; 19]$. Despite such a variety of tools. there is an extremely underestimated range of technologies that can not only improve the quality of educational services and the quality of professional training of future specialists. but also significantly increase the motivation of students to acquire and master key competencies of a general and special nature.

Thus. a number of problematic issues related to providing the system of higher professional education with modern pedagogical gaming and other (information and communication. educational. digital. etc.) technologies are formed. Their active and purposeful implementation will allow all higher education institutions in the country to form a new concept of development and reach a higher level. as well as develop the potential hidden until then for the formation of new systems. individual tools and mechanisms for interaction with various social institutions $[16 ; 22 ; 25]$. According to this. it would be fair to designate the above thesis as a key problem of the study.

\subsection{The objective of the work}

The above problem is reflected in the works of many domestic and foreign authors. But. despite this. quite a small number of problems from a number of the previously mentioned ones have been solved (even in the form of a theoretical or hypothetical justification).

This gave us a reason to build our own theoretical and practical research in such a way that. based on the theoretical material. we can present new practical data that can complement the pedagogical base. The theoretical basis of the research is the work of such domestic and foreign authors as G.S. Altshuller. B.P. Baydenko. V.P. Bespalko. I.P. Volkov. A.A. Getmanskaya. T.E. Zlygosteva. V.A. Kavera. M.V. Klarin. V. Knyaginin. N. Trunova. I.A. Kolesnikov. A.N. Dukkardt. D.S. Saenko. E.A. Sleptsova. K.V. Kanzychakov. S.D. Karakozov. A.Yu. Uvarov. N.Sh. Kozlov. N.S. Kramarenko. A.Yu. Kvashin. M.V. Mazay. I.Ya. Lerner. T.M. Mikhailenko. M.Yu. Oleshkov. B.A. Sazonov. G.K. Selevko. T.B. Feiling. A.S. Chernov. M.A. Choshanov. V.D. Shadrikov. I.S. Yakimanskaya and others.

The work of these researchers in the field of pedagogy. sociology. social psychology and philosophy formed the basis of this study and became a significant stage in the process of understanding the above-described issues.

They made it possible to supplement the theoretical basis of the research with the necessary theoretical and practical data. theses. and conceptual definitive elements that allow us to actualize the need to solve the described problem and come to a unified pedagogical consensus.

\section{Materials and the results of the research}

To implement the most effective conceptual research. we have identified a range of tasks that lead to the formation and solution of the most important goal of the entire work. These tasks include:

- identification of the specifics of modern pedagogical game technologies. as well as the specifics of the higher professional education system in which they are implemented;

- study of the experience of leading experts in the field of pedagogy. sociology. philosophy and other scientists involved in the development of this topic;

- identification of problems and potential for implementing these technologies in the process of professional training of specialists of different directions and levels;

- identification of the most effective and inefficient modern gaming technologies used in the system of higher professional education; 
- conducting analytical and reflexive research using the questionnaire method. which is the basis for the disclosure of the topic;

Based on the tasks described above. we define this research as follows: a complete study of the described problems. as well as identifying patterns and contradictions between the use of modern gaming technologies in the system of higher professional education.

With the development of various global processes. the field of education has undergone significant changes and has become focused on optimizing the educational process and the system of professional training of future specialists - University graduates. In this regard. along with positive trends. a number of problematic issues have been formed in relation to the motivation and involvement of students in the process of obtaining knowledge and skills. as well as to the acquisition of a specialty in an educational institution as a whole. Today. there is a disastrous tendency not to pass professional training in the traditional way - through official training at a University. but to get knowledge from third-party open resources: courses. webinars. master classes. etc.

In our opinion. this is due to the extensive entertainment media field. in which certain mechanisms of "stereotype destruction" function and develop. Thus. young people prefer easy ways to acquire knowledge. rather than more complex. but fundamental and. undoubtedly. better. In this regard. in modern education. there is a question about the need to develop a system of motivation tools and improve the quality of training of University students. A special place in this system is occupied by game technologies. which are actively reflected in both traditional and distance learning systems.

Zh.S. Abdykerov. O.M. Zamyatina and P.I. Mozgaleva believe that there are a number of reasons that can be traced to a decrease in the motivation of students. In their opinion. the decline in the quality of University students' training is due to:

- rather low level of professional orientated competence of students in the system of not only higher. but also general education. professional orientated competence is the most important element of the formation of professional culture of each person. It allows them to understand themselves and determine their place in the system of professional relationships. as well as develop their own system for achieving professional success. With a low career guidance culture. a potential student cannot determine their positive and negative qualities. objectively assess their professional capabilities;

- determination by parents of the place of vocational training of applicants. Most parents strive to implement their own ideas about the need to obtain a particular specialty. In this regard. they suppress the student's own motivation to obtain the relevant and most suitable specialty. which reduces the quality of assimilation of the knowledge they receive;

- low level of teachers' proficiency in modern pedagogical methods and tools. digital and information and communication technologies. Modern students need to be actively involved in various digital processes. At the same time. a special place is given to the teacher. who must have perfect digital literacy and digital competence. Due to this. the chances of attracting students' interest are significantly increased. which leads to a significant improvement in the quality of the disciplines acquired by the student;

- high level of students' knowledge of modern information and communication and digital technologies and gadgets that exceeds the level of a teacher. This aspect especially strongly affects the teacher's loss of authority. and therefore the authority is lost in the education system itself. which. according to many students. equips its tools with the latest technologies $[1 ; 2 ; 4 ; 5 ; 6 ; 12]$.

In our opinion. knowing about these reasons. it is only possible to correctly and accurately form a system of gaming technologies necessary to improve the quality of the educational process. since solving these problems will lead to a significant increase in competent and professional personnel. competitive and relevant specialists. 
Game technologies in modern pedagogical science are usually understood as a certain group of methods and special techniques of organizational and managerial pedagogical device and equipment of the educational process in the form of pedagogical games $[1 ; 2 ; 3$; $4 ; 6 ; 8 ; 10 ; 11 ; 12 ; 20 ; 21]$. It is believed that this system is designed to stimulate cognitive mental activity of both primary school students and students of higher education institutions. which indicates its versatility and flexibility. In addition. it activates the mechanisms of independent activity of students. develops their self-organization.

In their research on this topic. L.I. Saigusheva and I.S. Stryapukhina expressed the opinion that all game technologies used in the educational process today should be guided by certain principles of a didactic nature [21]. These include the following principles:

- the teacher becomes not only a leader and controlling body of the educational game process. but a partner. This emphasizes the parity beginning of the introduced game. which allows students to focus on their own place in the system of business or professional relations [16];

- through the active use of pedagogical games in the process of professional training of specialists. significant stimulation of cognitive activity occurs [10];

- students need to carry out independent search. navigation and processing activities in relation to the subject of the game and the object of research (if such is provided by the game). This greatly encourages them to improve their self-organization skills [5];

- the pedagogical game encourages students to apply their own life and educational experience in order to solve problematic issues and situations that arise during it [1];

- game activity in the conditions of professional training of modern specialists is quite spontaneous and cannot be predicted by a leading teacher. In this regard. there is a need for pedagogical flexibility and the ability to maintain parity interaction [20];

- gaming technologies are primarily aimed at forming a professional culture for future specialists [20].

Thus. the specifics of pedagogical games are reflected not only in the way the educational process is organized. but also in the methods and tools used by the teacher. The system of higher professional education is largely undergoing a certain range of changes. according to which the range of problems and crisis aspects related to both organizational and managerial and educational activities is clearly outlined in the conditions of modern pedagogical knowledge [3]. Today. there is an abundance of tools. aids and mechanisms of external and internal influence on the process of optimizing and modernizing the system of professional training of higher school students.

A special role in choosing a game technology is played by the classification of games. which has many types and subspecies. In our opinion. the most complete classification is provided by domestic researchers in this field. according to which all pedagogical games are divided into educational. cognitive. reproductive and communicative [23; 24]. They have a lot of differences based on their names and specifics. It is important to understand that games become effective only in the case of their complex and harmonious application in the educational process. as well as with a competent pedagogical combination of their own experience of such games and modern developing technologies.

At the same time. we note the importance that our online survey of teachers of the V.I. Vernadsky KFU acquires in this context. The fact is that. in our opinion. it is necessary to start with the introduction of game technologies from the set educational tasks that determine the vector of development of the educational system. In this case. game technologies show themselves as a significant tool for motivating and improving the quality of students' training. This gives us the right to believe that in the framework of this study. the most logical way would be to conduct a survey that can reflect the effectiveness or inefficiency of previously introduced gaming technologies in the educational process. 
In addition. we have compiled a list of questions that reflect the increase or decrease in the level of students' mastery of any competencies. depending on the presence or absence of game technologies in education. Focusing on the definition of such effectiveness allowed us to identify a number of priority areas for the implementation of educational games and made it possible to realize their practical significance for various groups of educational subjects. You can see the results of the online survey in table 1. which presents the data of a survey of teachers of one of the leading Crimean universities in the form of the percentage of effectiveness of game technologies within any educational structures (Table 1).

Table 1. Evaluation of the effectiveness of the introduction of gaming technologies in relation to various aspects of improving the quality of training of University students (\%).

\begin{tabular}{|l|l|l|l|l|}
\hline & $\begin{array}{l}\text { Absolutely } \\
\text { non } \\
\text { effective }\end{array}$ & $\begin{array}{l}\text { More } \\
\text { inefficient } \\
\text { than efficient }\end{array}$ & $\begin{array}{l}\text { More } \\
\text { efficient than } \\
\text { inefficient }\end{array}$ & $\begin{array}{l}\text { Absolutely } \\
\text { effective }\end{array}$ \\
\hline $\begin{array}{l}\text { The formation of } \\
\text { students' } 14.9 \\
\text { competences }\end{array}$ & 31.1 & $\mathbf{3 4 . 5}$ & 19.5 \\
\hline $\begin{array}{l}\text { Formation of } \\
\text { students' special } \\
\text { competencies }\end{array}$ & 19.6 & 21.3 & $\mathbf{3 0 . 4}$ & 28.7 \\
\hline $\begin{array}{l}\text { Development of new } \\
\text { competencies for } \\
\text { teachers }\end{array}$ & 14.7 & 27.3 & 15.4 & $\mathbf{4 2 . 6}$ \\
\hline $\begin{array}{l}\text { Checking and } \\
\text { evaluating students' } \\
\text { competencies }\end{array}$ & 10.5 & 10.5 & 32.5 & $\mathbf{5 5 . 5}$ \\
\hline $\begin{array}{l}\text { The increase in } \\
\text { motivation acquire } \\
\text { competencies }\end{array}$ & 14.5 & 16.7 & 33.6 & $\mathbf{3 5 . 2}$ \\
\hline $\begin{array}{l}\text { Improving the system } \\
\text { of training sessions }\end{array}$ & 20.9 & 11.4 & 29.5 & $\mathbf{3 8 . 2}$ \\
\hline $\begin{array}{l}\text { Improving the system } \\
\text { of extracurricular } \\
\text { activities }\end{array}$ & 22.6 & 17.4 & 19.4 & $\mathbf{4 0 . 6}$ \\
\hline
\end{tabular}

The results of the survey presented in the table "The evaluation of the effectiveness of the introduction of gaming technologies in relation to various aspects of improving the quality of training of University students" clearly demonstrate the positive and effective impact of gaming technologies on a wide variety of areas of activity of a University student:

- formation of students' general competencies (54\%);

- formation of students' special competencies $(59.1 \%)$;

- development of new competencies for teachers $(57.8 \%)$;

- checking and evaluating students' competencies (88\%);

- increasing motivation to acquire competencies $(68.8 \%)$;

- improving the system of training sessions (67.7\%);

- improving the system of extracurricular activities (60\%).

Based on this. we see that gaming technologies have proved themselves to be the best in all matters related to both the organization and management of the educational process. the formation of competencies for future specialists. as well as improving the quality of professional training for all students. 


\section{Conclusions}

The results obtained in the course of this study allowed us to draw a number of conclusions related to the use of gaming technologies as an important tool for motivating and improving the quality of University students ' training. First. the so-called gamification of the modern educational process of higher education contributes to a significant increase in students' motivation in various fields of study. as well as encourages their participation in the process of acquiring and mastering professional knowledge.

Secondly. through gaming activities in the process of professional training. students develop healthy competition. which will find its application in professional activities. which. of course. refers more to the positive impact of gaming technologies on the system of professional values of the person who is responsible for rejecting them.

Thirdly. game activity is one of the most effective and efficient tools for evaluating students' academic and professional activities. as it allows you to track the dynamics of its development and make certain conclusions and evaluation comments based on it.

Based on these main points. we believe that it would be fair to talk about the effectiveness of gaming technologies both in terms of motivating students and in terms of improving the overall quality of professional training of students. It is important to understand that game technologies used in the educational process. interacting with other educational technologies. make it possible to maximize all the previously described effects and significantly intensify the process of modernization of the higher professional education system.

\section{References}

1. Zh.S. Abdykerov, Gaming technology as a motivational tool and improve the quality of training of students, Higher education today, 5, 20-25 (2017)

2. G.S. Altshuller, Find an idea. Introduction to the TRIZ theory of inventive problem solving, p. 202 (Alpina Business books, 2007)

3. I.A. Babanova, Business games in the educational process, Scientific research in education, 7, 19-24 (2017)

4. V.P. Bespalko, Summands of pedagogical technology, p. 154 (Moscow: Prosveshchenie, 1989)

5. I.P. Volkov, Introducing students to creativity: from work Experience, p. 126 (Minsk. 1992)

6. A.A. Getmanskaya, Modular approach in the formation of key competencies in students, p. 3 (Internet-magazine "Eidos", 2005)

7. Yu.O. Goncharuk, U.S. Savinkina, P.I. Mozgaleva, O.M. Zamyatina, Use of Internet technologies in the organization of student project activities, Scientific and methodological electronic journal, 3, 26-33 (2013)

8. O.M. Zamyatina, P.I. Mozgaleva, Project-oriented training in the system of elite technical education at Tomsk Polytechnic University, In the collection: level training of Specialists: state and international standards of engineering education, p. 160-163 (National research Tomsk Polytechnic University, 2013)

9. N.A. Zvereva, Application of modern pedagogical technologies in secondary professional education, Innovative pedagogical technologies: materials of the II international conference, p. 161-164 (Kazan, 2015) 
10. T.E. Zlygosteva, Rating technology of modular training, Electronic resource, https://ito.su/2003/VI/VI-0-2394.html (2003)

11. V.A. Kavera, Modern pedagogical technologies in the system of additional education of children, Proceedings of the Saint Petersburg state University of culture and arts, 195, 159-170 (2013)

12. M.V. Klarin, Pedagogical technology in the educational process, p. 234 (Moscow: Knowledge, 1989)

13. V. Knyaginin, Competence approach and post-industrial labor market, Center for strategic development "North-West", 4, 32 (2005)

14. V. Knyaginin, N. Trunova, Competence approach and post-industrial labor market. Center for strategic development "North-West", 4, 32 (2005)

15. I.A. Kolesnikova, Fundamentals of technological culture of a teacher: a scientific and methodological guide for the system of professional development of educational workers, p. 288 (Publishing house "bustard", Saint-Petersburg, 2003)

16. I.Ya. Lerner, Pain points of the learning process, Soviet pedagogy, 5, 24-29 (1991)

17. T.M. Mikhailenko, Game technologies as a type of pedagogical technologies, Pedagogy: traditions and innovations, 1, 140-146 (2011)

18. M.Yu. Oleshkov, Pedagogical technology: the problem of classification and implementation, Professional and pedagogical technologies in the theory and practice of training: Collection of scientific papers, 5-19 (2005)

19. B.A. Sazonov, System of credit units: features of the organization and calendar planning of the educational process, Research center of quality problems of training of specialists, p. 104 (Moscow: Research center for training quality problems. Specialists, 2005)

20. L.I. Saigusheva, I.S. Striapuhina, Gaming technology as a means of familiarizing preschool children to self-care, International journal of experimental education, 7-2 (2014)

21. Yu.G. Tatur, Competence in the structure of the quality model of training specialists, Higher education today, 3, 21-26 (2004)

22. T.B. Feiling, Modern educational technologies in additional professional education, Izvestiya RSPU named after A.I. Herzen, 44, $485-489$ (2007)

23. M.A. Choshanov, Flexible technology of problem-modular training, p. 157 (Moscow: Public education, 1996)

24. V.D. Shadrikov, Development of junior schoolchildren in various educational systems, p. 232 (Moscow: Logos, 2011)

25. I.S. Yakimanskaya, The foundations of personality-oriented education, p. 220 (Moscow: BINOM, Knowledge lab., 2013) 